\title{
correspondence
}

\section{World energy organisation}

SiR,-Mr Greenhalgh (26 April, page 776) takes me to task for views 1 presented in a lecture and briefly reported in Nature (1 March, page 4). If Nature had given as much space to the report as to Mr Greenhalgh's letter, he would have found many of his arguments answered.

Mr Greenhalgh says there is a need for a greater concentration and coordination of the various projects of non-nuclear energy sources. 'This is exactly what I gave as one of the reasons for setting up a World Energy Organisation. At present there is no body in existence to carry out this task, and without a permanent institution the sporadic efforts will be highly inefficient, resulting in much duplication in some areas and gaps in others. But the proposed World Energy Organisation, as I envisage it, would do much more than promote research. It would advise countries of the type of energy most suitable for themincluding nuclear if deemed necessaryas well as provide funds for the implementation of the advice. Considering that energy is the life-blood of modern society, a Word Energy Organisation is essential. I am convinced that it would have been set up long ago if it were not for the International Atomic Energy Agency. It was a great mistake that the only truly international effort on energy should be concerned solely with one form of it; diversification of energy sources is vital for the world.

IAEA is doing a good job in fulfilling the objectives for which it was set up and I am not calling for its abolition, but it would be unwise to enlarge its terms of reference to include other energy sources. I am also not very happy about IAEA having two largely contradictory tasks: promoting nuclear energy and safeguarding against its misuse. I should like to see the latter be made part of the authority needed to implement the internationalisation of the sensitive parts of the nuclear fuel cycle, which I also advocated in my lecture.

This brings me to the problem of proliferation of nuclear weapons. $\mathrm{Mr}$ Greenhalgh is Honorary Secretary of APG (A Power for Good), an action group to promote nuclear energy, and is duty bound to minimise the danger of proliferation arising from the widespread use of nuclear energy, but his arguments carry no conviction. A nation intending to acquire nuclear weapons is not likely to make the preparations openly or in ways that can be easily detected. On the other hand, starting a nuclear power programme will enable it to acquire legitimately the technology and the materials for nuclear weapons. Moreover, this would also be the cheaper way because reactor-exporting countries will be only too eager to offer generous, longterm loans; in the long run this would be disastrous to the recipient country but it would hardly deter a regime which is bent on getting nuclear weapons.

The argument about the oil crisis is completely irrelevant. How can nuclear energy at its present rate of growth, become a substitute for oil when it runs out, or even have a significant effect on the oil crisis? Of course, there may be a confrontation over oil; there is also a multitude of other causes of conflict which may lead to war, but every sensible man can see that the consequences of any war would be far more disastrous if the combatants used nuclear weapons.

Finally, I don't need Mr Greenhalgh to remind me that the greatest danger to mankind comes from the nuclear arsenals of the great powers. I realised that danger even before the day of Hiroshima, and ever since $I$ endeavoured to do my utmost in the efforts to reduce it. But the hypocrisy in Mr Greenhalgh's argument is obvious: he draws attention to one source of danger in order to divert it from another source. Horizontal proliferation is a real issue, and its connection with nuclear power is generally recognised. If nuclear plants of the small nations did not present a potential danger, there would be no need for the NPT, the IAEA safeguards, the London Suppliers' Group, the INFCE, etc.

The avoidance of a nuclear holocaust is difficult enough with a few nuclear powers, but it would be hopeless if most nations became nuclear weapon states.

\section{London, $U K$}

J. RotBlat

\section{Interpreting shadowed relief}

SIR,-Everyone is familiar with photographs of the lunar surface showing craters, and with the fact that if such a picture is held upside down, flat topped mountains will be seen instead. The image is correctly interpreted as craters if the photographed light falls towards the viewer, and is wrongly interpreted as mountains if this light falls away from him. This reversal, sometimes called pseudoscopic illusion. seems to have been first described and correctly interpreted by Sir David Brewster (Rep. Br. Ass. Advmt. Sci. 30, pt $2,7-8 ; 1860)$, is discussed by Helmholtz (Handb. d. Physiologischen Optik, 3rd ed, ch 30, Voss, Hamburg/ Leipzig; 1910) and has received some attention in contemporary perception psychology (e.g. Rock, I., $A n$

Introduction to Perception, MacMillan, New York; 1975). If the orientation of a moon picture is midway between right and wrong the image will be found to switch between crater and mountain at irregular intervals, an effect sometimes described as image saltation. Faced with an $180^{\circ}$ misoriented moon picture, no amount of conscious effort by the observer, telling himself he ought to see craters will make the image switch. This orientation cue can only be overridden by a very strong contrary cue, such as a familiar image which can only be interpreted in one way. Thus, a picture of a chair will be seen correctly even if its shadow falls away from the viewer. A crater is not such an object since the alternative, a flat topped mountain, is not an inconceivable moon feature. Stereoscopic vision may also overcome the orientation cue, as illustrated by $\mathbf{R}$. L. Gregory (The Intelligent Eye, McGraw-Hill, New
York/London; 1970)

The electron microscopist examining shadowed replicas often finds himself in the frustrating situation of seeing the image in reverse relief, since there is normally no simple way of rotating a specimen grid without taking it out of the instrument and remounting it. Although the final photograph can always be correctly oriented, it is necessary to perceive relief correctly in order to understand what one is examining in the specimen itself. This is particularly critical for freeze-fracture biological replicas, in which the fracture plane can pass so as to yield both positive and negative relief. Often faced with this problem, I found a simple cue which can always be applied and is so powerful it invariably overcomes misorientation. It is simply to hold a small hand torch at the edge of, but within one's field of view, throwing light in the required direction. The light need not fall on the image; in fact the fluorescent screen of ordinary electron microscopes is so recessed this is impossible. Very little light is sufficient, so interference with dark adaptation can be minimal. Although a hand torch is unnecessary in the case of a photograph which can be oriented, it provides a good demonstration of the effectiveness of the cue. In particular, it will be found effective even in the presence of strong non-directional illumination.

Another form of this cue can be applied to lantern slides. It consists of a circular hole in the mask, just outside the border of the picture and in the sector from which light should come. For a $35 \mathrm{~mm}$ slide, the hole should be about $1.5 \mathrm{~mm}$ in diameter; for a $3 z^{\prime \prime} \times 4^{\prime \prime}$ slide, about $5 \mathrm{~mm}$ indiameter. The audience is not told the purpose of the resulting spot of light just outside the projected image, but will unconsciously interpret it as a "sun" and see the relief correctly. However, if orientation is arbitrary, it is preferable for the slide to be so made that light falls from the upper sector, so that the light spot cue and the orientation reinforce one another.

There are many applications of this principle: pictures of the moon and planet surfaces; air photographs, particularly those dealing with archaeological traces; oblique radar mapping; light microscopy with Nomarski optics; electron microscopy of shadow cast replicas. In published reproduction it may be urged that if there are no cartographic or other scruples, orientation should always be such that the apparent light falls towards the viewer, who will then be saved the trouble of using an artificial cue.

Instructions to authors in journals should request this. To avoid ambiguity, and particularly if photographs have to be printed in a misoriented direction, a small arrow should always be provided with the legend: direction of falling light (and not merely direction of light as this could be taken as pointing to the light source).

A. C. FABERGE

University of Texas at Austin. 